\title{
Vigilancia epidemiológica de sífilis y gonorrea
}

\author{
Syphilis and gonorrhea surveillance
}

\section{Introducción}

$\mathrm{L}$ as infecciones de transmisión sexual (ITS) son una de las principales causas de enfermedad aguda, infertilidad, discapacidad a largo plazo y muerte en el mundo. Tienen consecuencias médicas y psicológicas graves para millones de hombres, mujeres y niños ${ }^{1}$. La sífilis pude producir abortos, muerte neonatal y en recién nacidos trastornos como sordera, déficit neurológico, retraso del crecimiento y deformidades óseas ${ }^{2}$.

Las ITS imponen a los países tanto de recursos limitados como a los desarrollados, una carga enorme de morbilidad y mortalidad, ya sea de forma directa, por la repercusión que tienen en la calidad de vida, la salud reproductiva y la salud del niño, o bien indirecta por su función facilitadora de la trasmisión sexual del VIH y su impacto en las economías nacionales e individuales.

En Chile el Decreto Supremo $158^{3}$, establece que la sífilis (todas las formas clínicas) y gonorrea son infecciones de declaración obligatoria, universal, cuyo formulario de notificación debe enviarse en forma diaria a la Autoridad Sanitaria, por los establecimientos asistenciales públicos y privados.

En 1995, la Organización Panamericana de la Salud (OPS) generó el "Plan de acción para reducir la incidencia de sífilis congénita", cuyo objetivo fue alcanzar cifras menores o iguales a 0,5 casos por cada 1.000 nacidos, incluyendo los mortinatos. Para alcanzar esta meta se planteó reducir la incidencia de casos de sífilis a través de la detección oportuna y tratamiento de las mujeres gestantes. Actualmente en Chile, del total de casos de sífilis, $2 \%$ corresponden a casos de sífilis congénita ${ }^{4}$.

\footnotetext{
1 Pautas Vigilancia ITS ONUSIDA/OMS.

2 OPS. Metodología para Estudios de Subnotificación de Sífilis en mujeres embarazadas. 2005.

${ }^{3}$ Ministerio de Salud, 2004. Decreto Supremo No 158.

4 ENO/DEIS MINSAL.
}

El contar con una adecuada vigilancia a través de la cual se obtenga información epidemiológica, permite adoptar medidas de promoción de la salud y prevención de la infección, así como diseñar y evaluar los programas existentes.

\section{Aspectos generales}

\section{Sífilis}

\section{Características del agente}

El agente causal de la sífilis -enfermedad sistémica de reservorio humano exclusivo- es provocada por la bacteria Treponema pallidum, perteneciente al orden de Spirochaetales, familia Spirochaetaceae.

La sífilis es adquirida principalmente a través de contacto sexual y transplacentaria, pero además puede adquirirse por transfusión de sangre humana contaminada y por inoculación accidental directa. La historia natural de la infección se caracteriza por presentar tres etapas clínicas sintomáticas: sífilis primaria, secundaria y terciaria. Los períodos asintomáticos de la enfermedad se denominan sífilis latente. El diagnóstico precoz permite un tratamiento exitoso reduciendo las complicaciones y secuelas de la infección.

\section{Descripción clínica}

Sifilis primaria: Etapa de la infección por T. pallidum caracterizada por la presencia de una o más úlceras induradas, no dolorosas, llamadas chancro, que aparecen como una pequeña erosión que posteriormente se ulcera. Habitualmente es única, indolora, con bordes bien definidos, base indurada, con secreción serosa en su superficie, de localización genital y/o extragenital. Se asocia con adenopatía regional no dolorosa, única o múltiple. El chancro sin tratamiento desaparece espontáneamente en un período entre 3 y 8 semanas. 
La ubicación más frecuente del chancro primario en el hombre es el surco balanoprepucial, el glande y el cuerpo del pene. En la mujer, puede encontrarse en la vulva, paredes vaginales o cuello uterino. Las localizaciones extragenitales en ambos sexos se observan en ano, labios y mucosa oral.

El período de incubación promedio es de 21 días (rango entre 9 y 90 días).

Sifilis secundaria: Etapa de la infección que corresponde a la diseminación hematógena de T. pallidum. En aproximadamente $30 \%$ de los pacientes, la lesión primaria puede estar aún presente cuando aparecen las manifestaciones secundarias. El comienzo del periodo secundario se acompaña a menudo de síntomas similares a un estado gripal tales como fiebre, cefalea y decaimiento, acompañado de un rash cutáneo y linfadenopatías generalizadas. Las lesiones cutáneas más frecuentes pueden ser máculas, pápulas o lesiones pápulo escamosas, no pruriginosas, distribuidas simétricamente principalmente en tronco y extremidades. Es frecuente la localización palmoplantar. Las linfadenopatías se caracterizan por ganglios generalizados pequeños y no dolorosos. Sin tratamiento, estas manifestaciones cutáneas y mucosas desaparecen espontáneamente. Se presentan en episodios de tres a cuatro semanas de duración y en forma recurrente.

Estas manifestaciones se pueden encontrar dentro de los seis primeros meses después de la infección, habitualmente entre las semanas 6 y 8 .

En este período las lesiones son altamente infectantes por contener gran cantidad de treponemas en su superficie.

Sifilis latente: La persona infectada ha generado anticuerpos contra la bacteria y presenta ausencia de signos clínicos. La sífilis latente se puede dividir en latente precoz o latente tardía, dependiendo de cuánto tiempo la persona haya tenido la infección. Se diagnostica sifilis latente precoz, en aquellas personas que han estado infectadas durante al menos 12 meses, y sifilis latente tardia si la infección la presentan por más de 12 meses $^{5}$.

Siffilis terciaria: Etapa que se desarrolla años después de la infección primaria en pacientes no tratados o tratados inadecuadamente. Las manifestaciones de la sífilis terciaria son cardiovasculares con compromiso de grandes vasos y válvulas cardiacas, lesiones muco-cutáneas llamadas gomas sifilíticos que se pueden encontrar en piel, mucosas del paladar, faringe y tabique nasal y lesiones óseas que comprometen principalmente los huesos largos.

En esta etapa, la enfermedad no es trasmisible y los test no treponémicos pueden estar no reactivos. Además los treponemas son difíciles de encontrar y se entiende

El límite de un año en la clasificación de la sífilis corresponde a un consenso nacional. que las lesiones son producto de una reacción de hipersensibilidad.

Neurosifilis: se caracteriza por el compromiso del sistema nervioso central (SNC) por T. pallidum. Sus manifestaciones clínicas varían según el tiempo de evolución de la enfermedad. En sífilis de menos de un año, se manifiesta como sífilis meningovascular, meningitis sifilítica y neurosífilis asintomática. En sífilis de larga data (más de un año) se manifiesta como tabes dorsal y parálisis general progresiva.

La neurosífilis se puede manifestar en cualquier etapa clínica de la enfermedad, por lo tanto el estudio del líquido céfalo raquídeo (LCR) es crucial en población de riesgo ${ }^{6}$ y ante la sospecha clínica.

Sifilis congénita: infección que es adquirida por vía transplacentaria durante el período de gestación desde una madre infectada no tratada o inadecuadamente tratada. La gravedad de la infección se relaciona con el estadio de infección materna al momento del embarazo, la edad gestacional al momento de la infección, la carga de treponemas que infectan al feto y la oportunidad de la respuesta inmunológica de la madre.

Estados de la infección:

- Sífilis congénita precoz, se manifiesta desde la concepción hasta los dos primeros años de vida.

- Sífilis congénita tardía, se manifiesta después de los dos años de vida.

\section{Gonorrea}

\section{Características del agente}

El agente causal de la gonorrea es la bacteria Neisseria gonorrhoeae, diplococo Gram negativo, familia Neisseriaceae, cuyo reservorio, es exclusivo de los seres humanos. Esta bacteria es capaz de infectar diferentes tipos de mucosas, de preferencia la uretra en el hombre y el cuello uterino en la mujer, pudiendo además encontrarla en el recto, conjuntiva, faringe y en la vulva y vagina de la mujer.

La gonorrea es adquirida por contacto con exudados de las mucosas de las personas infectadas, principalmente por contacto sexual y en el parto si la madre está infectada (infección neonatal).

\section{Descripción clínica}

El período de incubación de 3 a 5 días (rango entre 1 y 20 días), y su periodo de transmisibilidad puede durar meses o años, especialmente en los casos asintomáticos.

\footnotetext{
${ }^{6}$ Se considera población de riesgo, todos los casos de sífilis tardía y pacientes infectados por VIH con sífilis en cualquier etapa, dado que existe evidencia clínica que indica que el riesgo de neurosífilis en estos últimos, aumenta hasta en 18 veces.
} 
La enfermedad se caracteriza por secreción purulenta o mucopurulenta. En hombres se manifiesta con descarga uretral purulenta abundante, disuria y aumento de la frecuencia miccional. Mientras que en la mujer, en la mayoría de los casos la infección es asintomática, se puede presentar con disuria y descarga vaginal. En $20 \%$ de los casos puede encontrarse invasión uterina en los primeros meses con síntomas de endometritis, salpingitis o peritonitis pélvica. Existen portadores asintomáticos en la mucosa anal, vaginal y faríngea.

Cabe destacar que cuando se diagnostiquen ITS en niños y niñas ésta pudo ser producto de contacto genital directo con personas infectadas en casos de abuso o violación sexual.

\section{Modalidad de vigilancia}

Objetivo: Conocer la incidencia, tendencia y características de estas infecciones en la población general y grupos específicos con el fin de implementar estrategias pertinentes de prevención, control y educación de la población.

Tipo de vigilancia: La vigilancia de sífilis y gonorrea es de tipo universal de caso confirmado según el Decreto Supremo 158/04.

Frecuencia de envío de la notificación: Diaria a la autoridad sanitaria Regional (SEREMI) y por sistema en línea desde la SEREMI al Ministerio de Salud.

\section{Notificación}

De acuerdo al Art. $1^{\circ}$, letra b) del DS No 158/2004, la notificación de sífilis y gonorrea es de carácter obligatorio en el área pública y privada. El médico tratante debe notificar cada caso confirmado a la SEREMI de Salud correspondiente y ésta al Departamento de Epidemiología del Ministerio de Salud, con todos los datos contenidos en el Formulario ENO (Enfermedades de Notificación Obligatoria). Según establece el Art. No 4 de este Decreto, al notificar las ITS se puede omitir el nombre y apellido del caso, indicándose en su reemplazo el RUT, así como su domicilio, consignándose en este caso sólo la comuna de residencia. Por lo anterior, todas las notificaciones de ITS deben incorporar obligatoriamente la variable RUT, incluidos los casos de sífilis congénita.

De acuerdo al Art. $8^{\circ}$ del DS No 158/2004, los laboratorios clínicos públicos y privados en que se efectúen exámenes que confirmen algunas de las enfermedades establecidas en el artículo $1^{\circ}$ deberán informar a las SE-
REMIs, sin perjuicio de que su resultado sea enviado al profesional o institución que lo solicitó. Esta información tiene como objetivo que la SEREMI coordine y derive los resultados a la red para que el profesional que atendió al caso realice la notificación.

De acuerdo al Art. $6^{\circ}$ del DS N²06/2007 "Reglamento Sobre Infecciones de Transmisión Sexual”, la notificación e investigación epidemiológica de las ITS, serán estrictamente confidenciales, de conformidad con las normas de la ley $\mathrm{N}^{\circ} 19.628$ y con el debido resguardo por parte de los funcionarios que tengan acceso a ellos del secreto profesional y del secreto estadístico establecido en la ley $\mathrm{N}^{\circ} 17.374$, obligación que no cesa por haber terminado sus actividades en ese campo.

\section{Consideraciones acerca de la notificación casos de sífilis}

La notificación de caso de sífilis congénita debe realizarse estrictamente de acuerdo a la definición de caso establecida en esta Circular. Todo caso notificado como sífilis congénita debe ser auditado según se describe en la "Norma Conjunta de Prevención de la Transmisión Vertical del VIH y Sífilis". Norma General Técnica No 0141 del 2012. La instancia responsable de estas auditorías es el "Comité Regional de Eliminación de la Transmisión Vertical de VIH y Sífilis”. Si el Comité descarta el caso, éste debe ser eliminado de los registros ENO.

\section{Exámenes reactivos en Centros/Bancos de sangrel}

Unidades de Medicina Transfusional y laboratorios

En caso de resultar exámenes reactivos para sífilis en:

Centros/Bancos de Sangre/Unidades de Medicina Transfusional: Éstos deben informar a la persona sobre el resultado reactivo de su examen o bien, de acuerdo a la organización establecida en cada región derivar los resultados a los Servicios de Salud para la entrega.

Laboratorios: Éstos deben enviar el resultado al establecimiento que originó la solicitud o al profesional solicitante. En el caso de exámenes procesados en laboratorios privados, deben informar el resultado reactivo a la persona.

Para realizar el diagnóstico de sífilis y clasificación de la etapa, se requiere contar con información clínica, antecedentes epidemiológicos y resultado de exámenes de laboratorio, por lo tanto, a nivel de Centros/Bancos de sangre/laboratorios la información sobre resultados reactivos se debe entregar sin establecer un diagnóstico de sífilis, señalando claramente la necesidad de confirmar o descartar la enfermedad, por lo cual, el usuario será derivado a un establecimiento de salud (público o privado) donde se realizará la evaluación diagnóstica, tratamiento, notificación epidemiológica por ENO si corresponde a un caso y búsqueda de contactos (según normativa vigente). La consejería de derivación del caso debe quedar registra- 
da en el Centro/Banco de sangre/Unidades de Medicina Transfusional o establecimiento que brinde la atención con la firma del paciente, como modo de verificación de la información entregada.

No se debe entregar un diagnóstico de sífilis basándose exclusivamente en los resultados de los exámenes. (Circular No 16 del 16/04/2010)

\section{Consideraciones acerca de la notificación casos de gonorrea}

Los casos de gonorrea deben ser notificados por el médico o profesional clínico que atienda a la persona y que realice el diagnóstico de acuerdo a la definición de caso confirmado establecida en la presente circular.

Neisseria gonorrhoeae se encuentra sujeta a vigilancia de laboratorio según el Artículo 9 del decreto Supremo 158 , por lo que los laboratorios públicos y privados que aíslen este agente, deberán enviar la cepa al Laboratorio de Bacteriología del Instituto de Salud Pública, para su confirmación y caracterización, acompañada del formulario de envío de cepas de la sección bacteriología (disponible en www.ispch.cl).

\section{Definiciones de casos}

Definición de caso sífilis: la definición de caso confirmado de sífilis varía en relación a las etapas en que se encuentre la persona, según se describe en las Tablas 1 y 2.

\section{Funciones y nivel de responsabilidad}

Establecimiento de Salud: El Delegado de Epidemiología será responsable de:

- Difundir la normativa de vigilancia al interior del establecimiento

- Velar que el médico o encargado de la notificación complete todas las variables del Formulario ENO de cada paciente que cuyo diagnóstico de sífilis o gonorrea sea confirmado.

- Asegurar la calidad, integridad y oportunidad de la información remitida.

- Remitir la información en forma diaria a Epidemiología de la SEREMI de Salud correspondiente.

- Difundir a los equipos de salud los boletines epidemiológicos elaborados a nivel nacional o regional.

\section{Servicios de Salud}

- Trabajar en forma coordinada con la SEREMI de Salud.

- Retroalimentar a los directores de establecimientos y delegados de epidemiología sobre la calidad de los datos.
- Asegurar que cada caso notificado de sífilis congénita sea auditado en el "Comité Local de Eliminación de la Transmisión Vertical de VIH y sífilis"

- Tomar acciones correctivas, cuando corresponde e informar a la SEREMI de Salud.

- Supervisar el seguimiento de contactos en cada caso índice.

\section{Epidemiología de la SEREMI de Salud}

- Difundir la normativa de vigilancia actualizada a los establecimientos de salud.

- Velar por el adecuado funcionamiento del sistema de vigilancia cursando las sanciones correspondientes de no cumplirse la normativa vigente.

- Asegurar la calidad, integridad y oportunidad de la información epidemiológica remitida a nivel nacional

- Asegurar que cada caso notificado de sífilis congénita sea auditado por el "Comité Regional de Eliminación de la transmisión vertical de VIH y sífilis".

- Asegurar que todos los casos de sífilis congénita confirmados por el “Comité Regional de Eliminación de la transmisión vertical de VIH y sífilis” sean consistentes con los casos notificados por ENO.

- Verificar que en cada caso notificado como sífilis congénita, exista la notificación de sífilis en la madre.

- Retroalimentar de información a los niveles locales

- Digitar la información del Formulario ENO en el sistema en línea.

- Coordinar instancias de trabajo con los Servicios de Salud, direcciones médicas de establecimientos públicos y privados para análisis, complemento de información, evaluación de los procesos de vigilancia epidemiológica y corrección de los mismos.

- Elaborar diagnósticos epidemiológicos regionales y comunales de la situación de estas enfermedades y difundirlas a nivel de personal sanitario, organismos intersectoriales y comunidad.

\section{Ministerio de Salud (DEIS y Departamento de Epidemiología)}

- Difundir normativa vigente y mantenerla vigente.

- Monitorear y evaluar el funcionamiento de la vigilancia de sífilis y gonorrea.

- Consolidar y analizar la información a nivel nacional.

- Elaborar informes epidemiológicos nacionales.

- Difundir la información

\section{Indicadores de la calidad de la vigilancia epidemiológica}

La vigilancia epidemiológica debe ser sistemática, permanente y ajustada según definición de caso a vigilar. Es por ello que los datos ingresados en los formularios de notificaciones deben mantener las características de una adecuada vigilancia: consistencia (datos lógicos), 


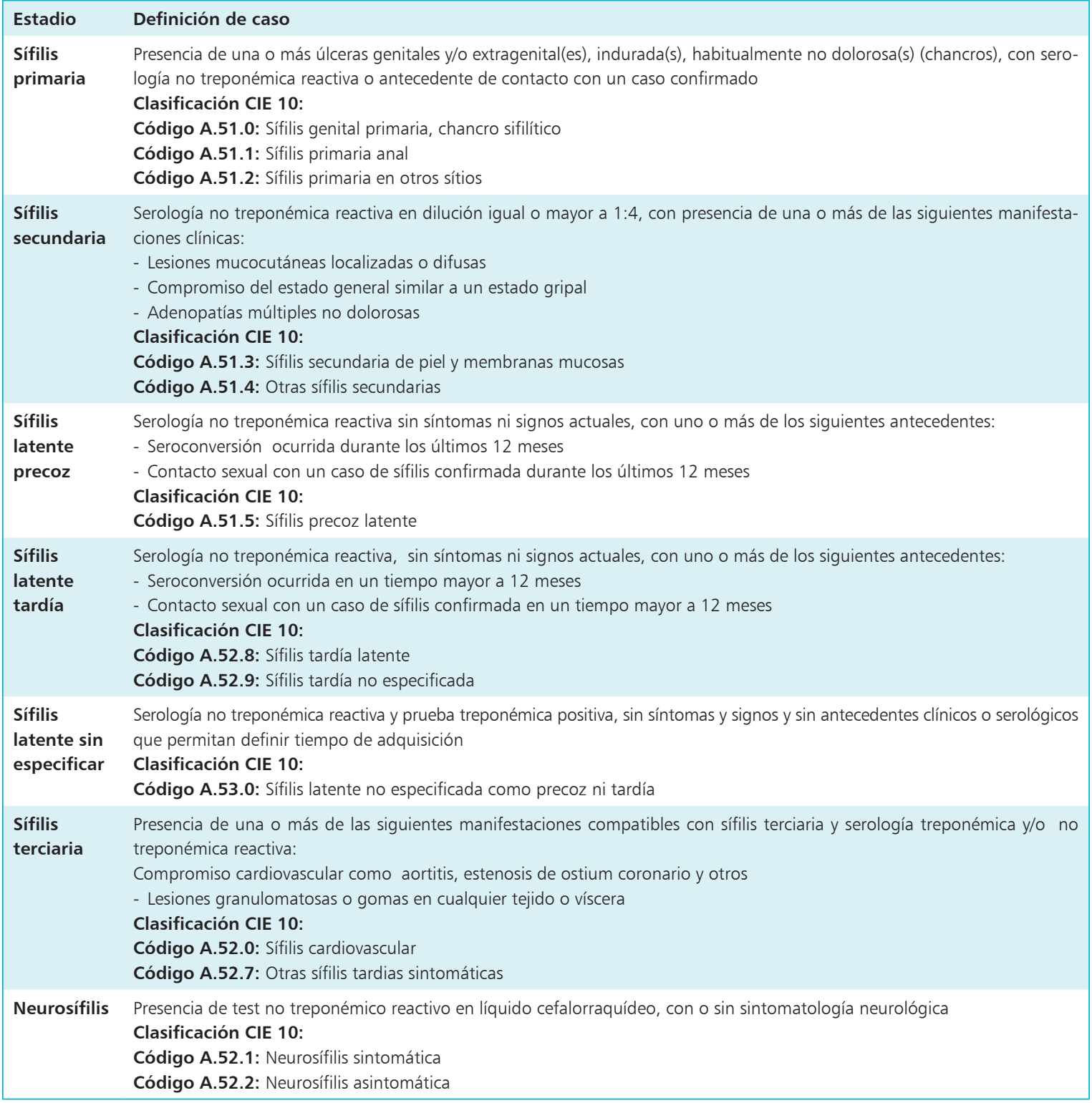

pertinencia (referidos a los objetivos de la vigilancia), exactitud ( $\sin$ errores), oportunidad (disponible en el momento preciso) e integridad (contener todos los datos y variables necesarias).

Para esta vigilancia, se han establecido los siguientes indicadores de calidad de la vigilancia:

Formularios de notificación completos: El formulario ENO debe contar al menos con la información pertinente a las siguientes variables: fecha de notificación, establecimiento desde el cual se realiza la notificación, autoridad sanitaria correspondiente, RUT, sexo, fecha de nacimiento, edad, ocupación, comuna de residencia, nacionalidad, diagnóstico, confirmación diagnóstica, condición de embarazo y profesional que notifica el caso. Se espera que al menos $85 \%$ de la información en el formulario debe estar completa. Indicador: $\mathrm{N}^{\mathrm{o}}$ de formularios completos/ Total de casos notificados por enfermedad.

Formularios de notificación con información coherente: El formulario ENO debe contener información coherente de acuerdo a las variables consignadas: la condición de embarazo debe pertenecer exclusivamente al sexo femenino y debe ser coherente a la edad. La notificación de sífilis congénita y el resto de las clasificaciones de sífilis deben ser coherentes a la edad. Se espera 


\section{Tabla 2. Definición de caso de sífilis congénita}

\begin{tabular}{|c|c|}
\hline & $\begin{array}{l}\text { Serología no treponémica reactiva en los } 2 \text { primeros años de vida con antecedente de madre con sífilis confirmada no } \\
\text { tratada o inadecuadamente tratada durante la gestación, según normativa vigente y alguna de las siguientes condi- } \\
\text { ciones: } \\
\text { - Test no treponémico reactivo a cualquier dilución, con alteraciones de laboratorio y/o clínicas compatibles con } \\
\text { hepatoesplenomegalia, rash máculopapular, con compromiso de palmas y plantas, pénfigo sifilítico, coriza serohe- } \\
\text { morrágica, fisuras periorales y/o perianales (rágades), condilomas planos, pseudoparálisis de Parrot, compromiso del } \\
\text { SNC. } \\
\text { Clasificación CIE 10: } \\
\text { Código A.50.0: Sífilis congénita precoz sintomática. } \\
\text { - Test no treponémico reactivo mayor o igual a } 2 \text { diluciones comparado con el test no treponémico de la madre, con } \\
\text { lactante sin sintomatología. } \\
\text { Clasificación CIE 10: } \\
\text { Código A.50.1: Sífilis congénita precoz latente. }\end{array}$ \\
\hline rdía & $\begin{array}{l}\text { Detección de serología no treponémica reactiva después de los } 2 \text { primeros años de vida, con antecedente de madre con } \\
\text { sífilis confirmada durante la gestación no tratada o inadecuadamente tratada y sin tratamiento al nacer, en ausencia } \\
\text { de contacto sexual y alguna de las siguientes condiciones: } \\
\text { - Ausencia de signos y síntomas. } \\
\text { Clasificación CIE 10: } \\
\text { Código A.50.6: Sífilis congénita tardía latente. } \\
\text { - Presencia de estigmas sifilíticos como queratitis intersticial, granulomas necrosantes (gomas), compromiso cardio- } \\
\text { vascular, dientes de Hutchinson, molares en mora, perforación del paladar duro, nariz en silla de montar, tibias en } \\
\text { "sable", opacidades corneales, atrofia óptica, sordera por compromiso del VIII par craneal, articulación de Clutton } \\
\text { (sinovitis e hidroartrosis de rodillas). } \\
\text { Clasificación CIE 10: } \\
\text { Código A.50.5: Otra forma de sífilis congénita tardía sintomática o } \\
\text { Código A.50.3: Oculopatía sifilítica congénita tardía. } \\
\text { - Presencia de test no treponémico reactivo en líquido cefalorraquídeo, con o sin sintomatología neurológica } \\
\text { Clasificación CIE 10: } \\
\text { Código A.50.4: Neurosífilis congénita tardía. }\end{array}$ \\
\hline
\end{tabular}

\section{Tabla 3. Definición de caso de gonorrea}

Caso confirmado: presencia de examen de laboratorio microbiológico, inmunoenzimático o de biología molecular que señale infección por N. gonorrhoeae, con y sin sintomatología o antecedente de contacto con un caso confirmado.

Clasificación CIE 10:

Código A.54: Infección gonocócica

A54.0 Infección gonocócica del tracto genitourinario inferior sin absceso periuretral o de glándula accesoria

A54.1 Infección gonocócica del tracto genitourinario inferior con absceso periuretral y de glándulas accesorias

A54.2 Pelviperitonitis gonocócica y otras infecciones gonocócicas genitourinarias

A54.3 Infección gonocócica del ojo

A54.4 Infección gonocócica del sistema osteomuscular

A54.6 Infección gonocócica del ano y del recto

A54.8 Otras infecciones gonocócicas

A54.9 Infección, gonocócica, no especificada

que $100 \%$ de las notificaciones de sífilis congénita y en mujeres embarazadas se notifiquen en forma correcta. Indicador: $\mathrm{N}^{\circ}$ de notificaciones coherentes/Total de casos notificados por enfermedad.

\section{Laboratorio}

\section{Sífilis}

Existen dos tipos de exámenes de laboratorio, que permiten realizar el diagnóstico de sífilis, los no trepo- némicos, que se utilizan preferentemente como técnicas de tamizaje diagnóstico y para seguimiento y los treponémicos, que se utilizan como medio de confirmación diagnóstica.

\section{No treponémicos (reagínicos)}

No determinan anticuerpos específicos frente a $T$. pallidum y se basan en antígenos compuestos. Un examen no treponémico reactivo, sin otra evidencia de sífilis, no confirma una infección por sífilis. En esta categoría se encuentran: 
- VDRL (Venereal Disease Research Laboratory): corresponde a una reacción antígeno-anticuerpo, mide anticuerpos IgM e IgG del material lipoidal liberado de las células hospederas dañadas, así como material, semejante a lipoproteína y posiblemente cardiolipina, liberado desde los treponemas. Los anticuerpos antilipoidales son anticuerpos que se producen no sólo como consecuencia de la sífilis, sino que en algunos casos puede asociarse a otras condiciones en las cuales hay daño de los tejidos.

- RPR (Rapid Plasma Reagin): Este procedimiento corresponde a una reacción antígeno-anticuerpo. Mide anticuerpos IgG e IgM producidos en respuesta al material lipoidal liberado desde las células dañadas del hospedero, así como en respuesta a material parecido a proteínas, liberado desde los treponemas. Al igual que el VDRL, los anticuerpos antilipoidales que detecta este examen, pueden no sólo ser producto de la sífilis, sino también en respuesta a otras enfermedades

\section{Pruebas treponémicas}

Detectan los anticuerpos específicos contra T. pallidum y su utilidad está orientada a confirmar el contacto de la persona con el T. pallidum. Estas pruebas una vez que se hacen reactivas, permanecen reactivas para toda la vida. Por tanto no son útiles al momento de definir enfermedad actual de enfermedad antigua. En esta categoría se encuentran:

- FTA-Abs (Fluorescent Treponemal Antibody Absorption): Es una técnica de anticuerpos fluorescentes indirecta empleada como examen confirmatorio de sífilis, que emplea T. pallidum como antígeno.

- MHA-TP (Microhemaglutination Assay for Antibody to T. pallidum): Es una técnica de hemoaglutinación pasiva basada en la aglutinación de eritrocitos sensibilizados con el antígeno de T. pallidum por los anticuerpos presentes en el suero del paciente. Se emplea como examen confirmatorio, pero es menos sensible en la etapa precoz y en la tardía de la enfermedad que el FTA-Abs.

- Test de ELISA (Enzyme-Linked Immunosorbent Assay.) y de Quimioluminiscencia: Son técnicas de inmunoensayo que detectan anticuerpos treponémicos específicos, y se caracterizan por estar disponibles en plataformas altamente automatizadas, por lo que son técnicas que se han recomendado de elección para tamizaje en donaciones de sangre.

- Inmunocromatografía: Es una técnica cualitativa para detección de anticuerpos específicos contra T. pallidum. Se basa en un sistema de reacciones inmunológicas realizadas por migración sobre una banda. Cuando está presente el anticuerpo se forma un conjugado antígeno anticuerpo que migra y se va a fijar a zona de resultado dando una línea coloreada.

\section{Gonorrea}

- Cultivo: N. gonorrhoeae es un agente muy lábil frente a las condiciones ambientales, por lo que el cultivo requiere de la siembra inmediata de las muestras o su inoculación en un medio de transporte apropiado como el agar Amies. El cultivo debe ser efectuado en un medio selectivo como el agar Thayer-Martin. El cultivo de $N$. gonorrhoeae es de gran importancia epidemiológica ya que permite que el laboratorio de referencia ISP realice las pruebas de susceptibilidad antimicrobiana necesarias para la elaboración de las pautas de tratamiento nacionales. El reciente reporte internacional de cepas resistentes a ceftriaxona, refuerza la importancia de la realización del cultivo y el cumplimiento de esta vigilancia de laboratorio.

- Tinción de Gram: Permite la identificación de diplococos Gram negativos intracelulares tanto en secreción uretral, conjuntival, endocervical como en otras. La sensibilidad del Gram es de 90\% con una especificidad de $99 \%$, en hombres sintomáticos, en cambio en mujeres la sensibilidad de la tinción de Gram es de 50\% y la especificidad es del $95 \%$, por lo tanto requieren de cultivo de secreción endocervical en medio selectivo (Thayer Martin). En hombres y mujeres el estudio de secreción rectal siempre requiere confirmación por medio de cultivo.

- Pruebas moleculares: Son técnicas rápidas y muy sensibles que permiten la detección de material genético de $N$. gonorrhoeae directamente en muestras clínicas. Clásicamente se dividen en pruebas de hibridación y de amplificación. Es de vital importancia el estricto seguimiento de las instrucciones de toma de muestra y transporte indicadas por el fabricante de la prueba diagnóstica, ya que el no cumplimiento de éstas puede afectar gravemente el desempeño de estas pruebas moleculares.

- Test de inmunoensayo en orina y secreción (inmunofluorescencia, ELISA y otros): Se discute su aplicabilidad, su desempeño es modesto por lo que su utilización ha ido en franca disminución en los últimos años.

\section{Tratamiento}

El tratamiento de sífilis y gonorrea se detalla en las "Normas de Manejo y Tratamiento de Infecciones de Transmisión Sexual (ITS)", Norma general técnica N ${ }^{\circ} 103$ MINSAL. aprobada por D.E N²42/2008 (pág 74-75;7980; 84-87 para sífilis y pág 91 para gonorrea).

\section{Prevención y Manejo}

La prevención y el control de las ITS como la sífilis y la gonorrea contemplan acciones destinadas a la pobla- 
ción y al sistema de salud, con el objetivo de disminuir la incidencia de casos nuevos y cortar la cadena de transmisión.

A la población van dirigidas las estrategias de promoción de conductas sexuales seguras, adopción de medidas preventivas y fomento de la consulta precoz. Al Sistema de Salud van dirigidas las normativas para la pesquisa, diagnóstico, tratamiento y seguimiento del caso índice y sus parejas.

Las conductas que permiten la prevención de la adquisición de las ITS por vía sexual son el uso correcto y consistente del preservativo en todas las relaciones sexuales, la mutua exclusividad en la pareja asegurándose ambas personas de no tener ITS o la elección de mantener abstinencia sexual. Es necesario considerar en los mensajes educativos la incorporación de medidas preventivas acordes a las prácticas de sexo oral y anal, que cada vez tienen una mayor aceptación en la población de adolescentes y jóvenes.

Las medidas que evitan la transmisión de la sífilis y por ende el corte de la cadena de transmisión, son la pesquisa y el tamizaje selectivo a diversas poblaciones, entre las que destacan las mujeres gestantes, para prevención de la transmisión vertical (de madre a hijo/a), los consultantes de ITS, las personas que ejercen el comercio sexual y los donantes de sangre, entre otros.

Al pesquisar un caso de sífilis se indica evaluación, control y tratamiento de sus contactos sexuales de manera de cortar la cadena de trasmisión y prevenir la reinfección (descrito en "Normas de Manejo y Tratamiento de Infecciones de Transmisión Sexual (ITS)", Norma general técnica $\mathrm{N}^{\circ} 103$ MINSAL, aprobada por D.E N424/2008, pág 49-51).

Las personas pueden acceder al examen de detección de sífilis y gonorrea en toda la red pública y privada en atención.

Respecto de la donación y transfusión de sangre, en Chile la sangre donada es sometida a exámenes para detectar la sífilis a partir del año 1983.

Esta circular entrará en vigencia a contar de la fecha de recepción, por lo que se instruye definir los mecanismos necesarios para asegurar su cumplimiento.

Con el objeto de fortalecer y mejorar la calidad de la notificación de casos de sífilis y gonorrea, solicito a usted dar la más amplia difusión a esta Circular y velar porque se implementen las medidas contenidas en ésta. 